\title{
Oral manifestations of ellis-van creveld syndrome. A rare case report
}

\author{
Juan-Francisco Peña-Cardelles ${ }^{1}$, David A. Domínguez-Medina ${ }^{2}$, Jorge A. Cano-Durán ${ }^{3}$, Daniel Ortega-Con- \\ cepción ${ }^{4}$, José-Luis Cebrián ${ }^{5}$
}

${ }^{1}$ DDS, Oral Medicine Postgraduate in Complutense University of Madrid. Oral and Maxillofacial Surgery Service, Alcorcon Southern Hospital

${ }^{2} \mathrm{MD}$, Oral and Maxillofacial Surgery Service, Alcorcon Southern Hospital

${ }^{3}$ DDS, Oral Medicine Postgraduate in Complutense University of Madrid

${ }^{4}$ DDS, Oral Medicine Postgraduate in Complutense University of Madrid

${ }^{5} \mathrm{PhD}$, MD, DDS. Head of Oral and Maxillofacial Surgery Section of the La Paz University Hospital. Co-Director of the Service of Maxillofacial Surgery and Dentistry of Hospital la Luz. Head of the Oral and Maxillofacial Surgery Service, Alcorcon Southern Hospital

\section{Correspondence:}

Universidad Rey Juan Carlos

Avenida de Atenas s/n, 28922 Alcorcón, Madrid

juanfranciscopenacardelles@gmail.com
Peña-Cardelles JF, Domínguez-Medina DA, Cano-Durán JA, Ortega-Concepción D, Cebrián JL. Oral manifestations of ellis-van creveld syndrome. A rare case report. J Clin Exp Dent. 2019;11(3):e290-5.

http://www.medicinaoral.com/odo/volumenes/v11i3/jcedv11i3p290.pdf

Received: 01/01/2019 Accepted: 04/02/2019

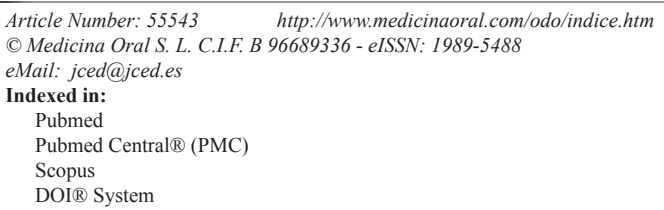

\begin{abstract}
Ellis-van Creveld syndrome (EVC) or chondroectodermal dysplasia is an autosomal recessive disorder, characterized by dwarfism, polydactyly, hypoplastic fingernails and congenital heart defects, finding in most of the cases orofacial anomalies. We describe a clinical case of a 9 year old male patient diagnosed with EVC who visited our Maxillofacial private consultation at Alcorcon Southern Hospital, presenting typical oral manifestations such as dental agenesis, delayed eruption, hypoplasia of the enamel, dental dysmorphism, taurodontism and supernumerary teeth.

EVC syndrome is a rare disease and requires a multidisciplinary approach. Oral features are constant and requires the jointly performance of Odontologist and Maxillofacial surgeon aiming to get an appropriate treatment sequence surgery-orthodontics in order to achieve a suitable functional result to improve the quality of life of these patients.
\end{abstract}

Key words: Ellis-Van creveld syndrome, chondroectodermal dysplasia, oral manifestations, craniofacial manifestations.

\section{Introduction}

Ellis-Van Creveld syndrome or chondroectodermal dysplasia is a rare disorder, autosomal recessive (1-3), characterized by dwarfism, postaxial polydactyly of the hands and feet, severe dystrophy of the fingernails and congenital heart defects in about $50-60 \%$ of the cases (4-6).
First description of the syndrome was made by the Pediatricians Richard Ellis and Simon Van 433Creveld in 1940. It is the result of a genetic defect located in chromosome $4 \mathrm{p} 16$. (4) The prevalence varies from $1 / 1000000$ in general population to $7 / 1500000$ in amish population (Lancaster, Pennnsylvania, USA) (2,5). Orally, the syndrome features consist of teeth of abnor- 
mal form (microdontia, conical teeth, dens in dente, taurodontism), supernumerary teeth, hypoplasia of the enamel, neonatal teeth in about $30 \%$ of the cases, as well as premature exfoliation of the teeth, malocclusion, multiple frenula, absent vestibular sulcus, submucous clefts, hypertrophic frena and labial frenula, dystrophic philtrum (6-8).

The present article describes the case report of a child patient diagnosed with EVC, presenting the major spectrum of oral features described in literature. Our patient was object of maxillofacial surgical treatment as a first stage sequence that will include combined orthodontic and restauration odontology. We emphasize the importance of a multidisciplinary approach for the correct management of these patients dental problems.

\section{Case report}

A 9 year old male patient was brought by his father, to our Maxillofacial private consultation at Alcorcon Southern Hospital, referred from Public medical institution, seeking for evaluation and possibility of treatment, the reason of consult was the abscense of eruption of the permanent superior incisors. The diagnosis of EVC was made at birth, in the public institution where he was referred from. There was no family background of the disease, he had healthy parents and brothers. The parents are originally from Morocco and consanguinity related in second degree.

Among the patient's medical background, he presented heart congenital disease: interventricular communication that closed spontaneously and interauricular communication, surgically corrected at the age of three.

At the age of four, surgical correction of epispady was performed and at the the age of nine, surgical correction of both inferior limbs axis was performed "genu valgum deformity".
At the clinical exploration, he presented short disarmonic stature $(110 \mathrm{~cm})$, both superior and inferior short limbs with bilateral hexadactyly and hypoplastic fingernails.

Facial exploration, revealed normo-brachicephaly, normal eyelid fissures, wide nasal tip and narrow nostrils (Fig. 1).

Intraoral exploration revealed, agenesis of lateral superior and inferior incisors [12,22,32,42], dysmorfism compatible with conical teeth at inferior incisors and canines $[31,33,41,43]$, fusion between a superior incisor (11) and a supernumerary tooth (mesiodens). As for the soft tissues, multiple frenum, macroglossia and glososquissis can be find (Fig. 2).

Furthermore, retention of maxillary incisors was present, due to the presence of a central supernumerary tooth. For this purpose, the retention was treated by extraction of the included central supernumerary tooth, under general anesthesia.

Radiografically, certain degree of taurodontism was present at the permanent superior first molars and more discretely at the permanent inferior first molars (Fig. 3). In total 2 central supernumerary teeth were present. Maxillary compression was also evidenced

It is remarkable the maloclussion with a tendency to a class III and anterior crossbite.

\section{Discussion}

In our reported case, there was no family medical pathologic background related, although there may be a history of consanguinity in up to $30 \%$ of cases. 7

Among the published cases of the last decade, describing oral manifestations of the syndrome, the prevalence was $31.5 \%$ of men and $68,42 \%$ of women (Table 1 ).

In the international literature, it is characteristic a tetrad, present in our patient, consisting of: dwarfism, bilateral
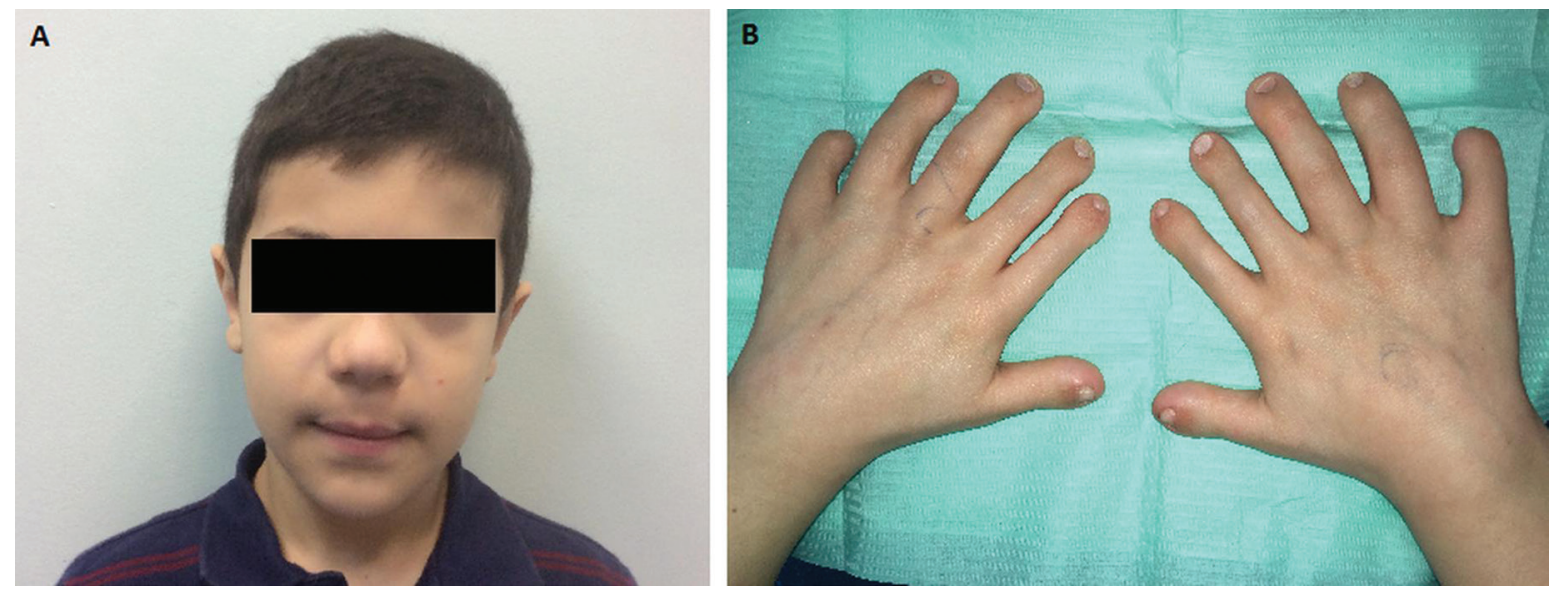

Fig. 1: A. Extraoral vision, B. Intraoral vision: Polidactyly in both hands, as well as severe neil displasia. 

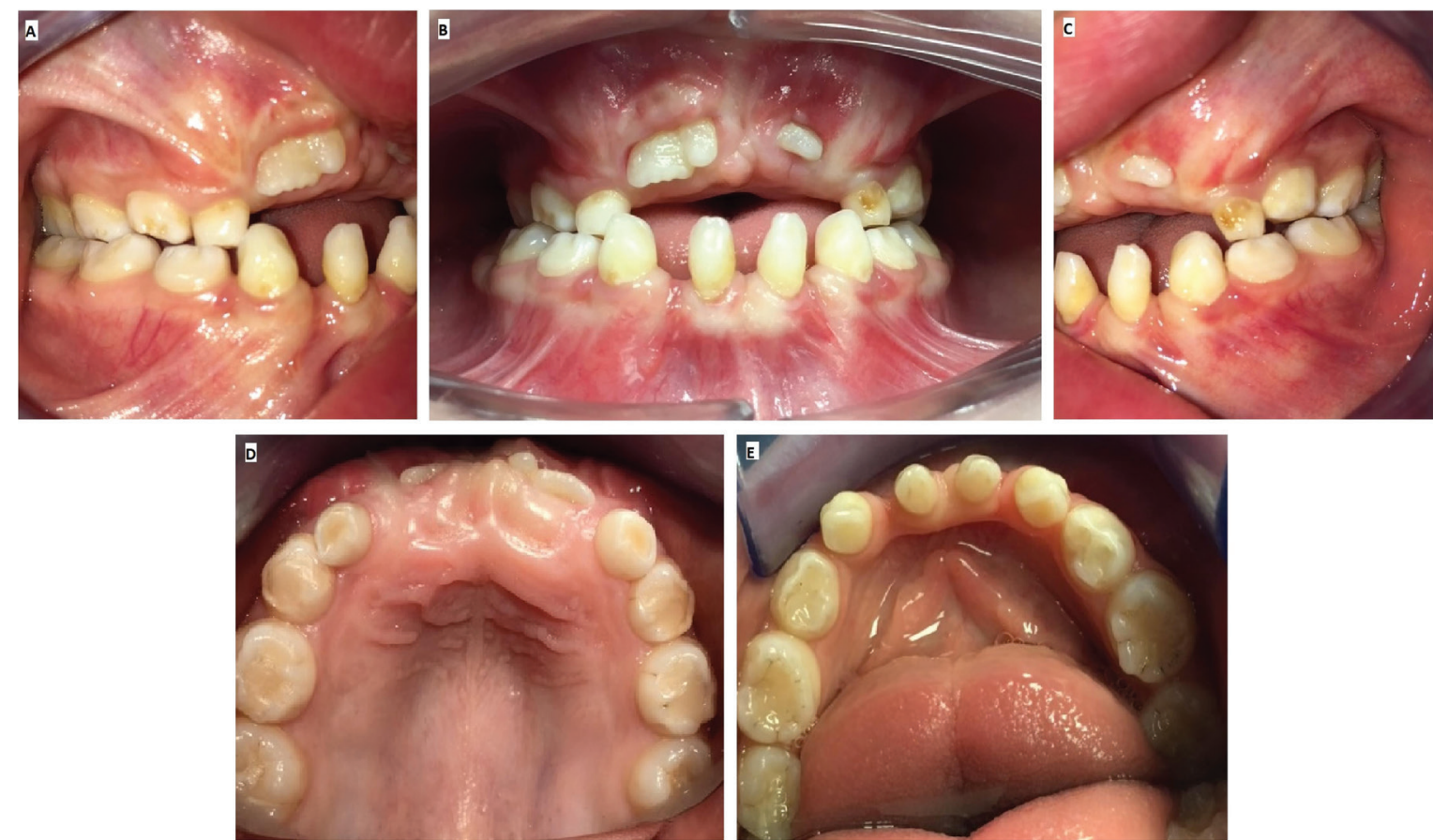

Fig. 2: Intraoral vision A. Right side view, B. Front view, C. Left side view, D. Superior occlusal view, E. Inferior occlusal view.
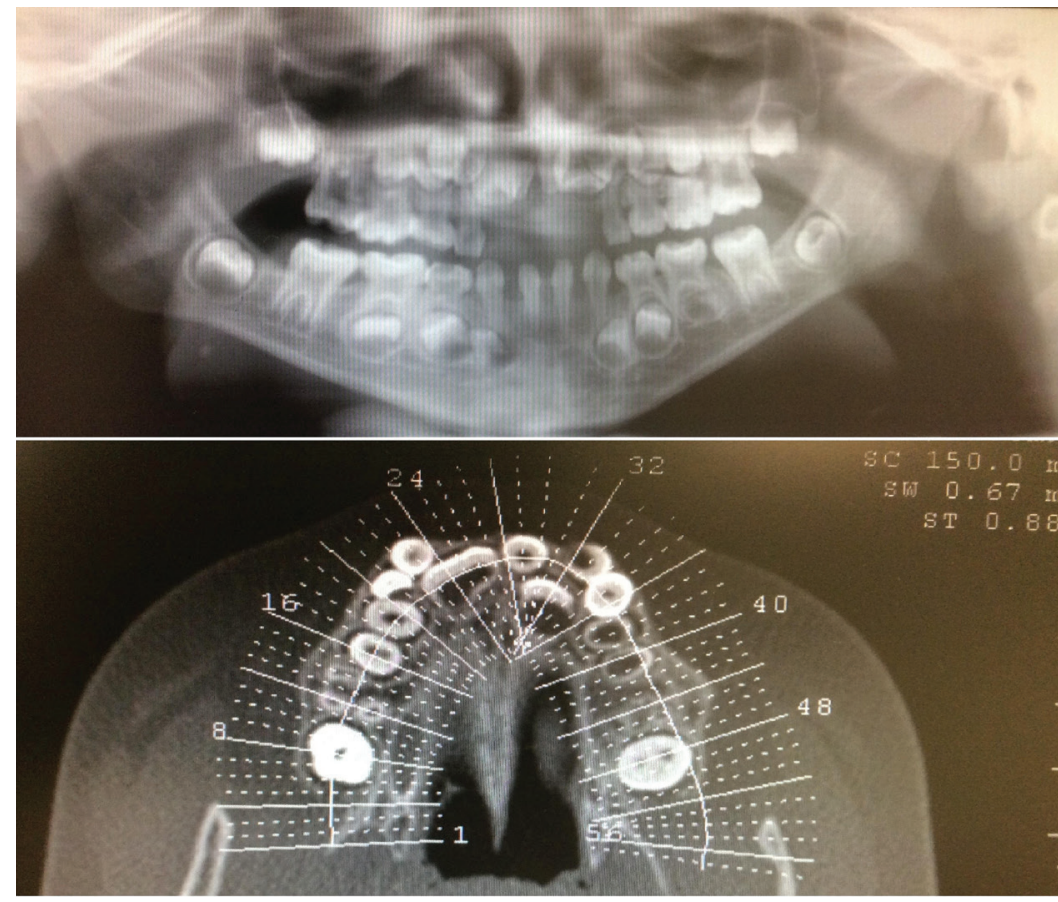

Fig. 3: Orthopantomography and computer tomography. Both were performed with a diagnostic purpose prior to the surgery of mesiodens extraction.

polydactyly of the hands, ectodermal dysplasia (disorder in fingernails, teeth) and cardiac congenital malformations $(2,4-6,10)$.

It is remarkable the varied spectrum of oral features involving both soft tissues and teeth, that are constant (Tables 1-3), nevertheless there are unusual findings like the presence of taurodontism (Fig. 3) also present in our case. It is important to comment that development of taurodontism and conical form of teeth could be due to one single genetic alteration or multiple ones and be important to make differential diagnosis with other syndromes. 


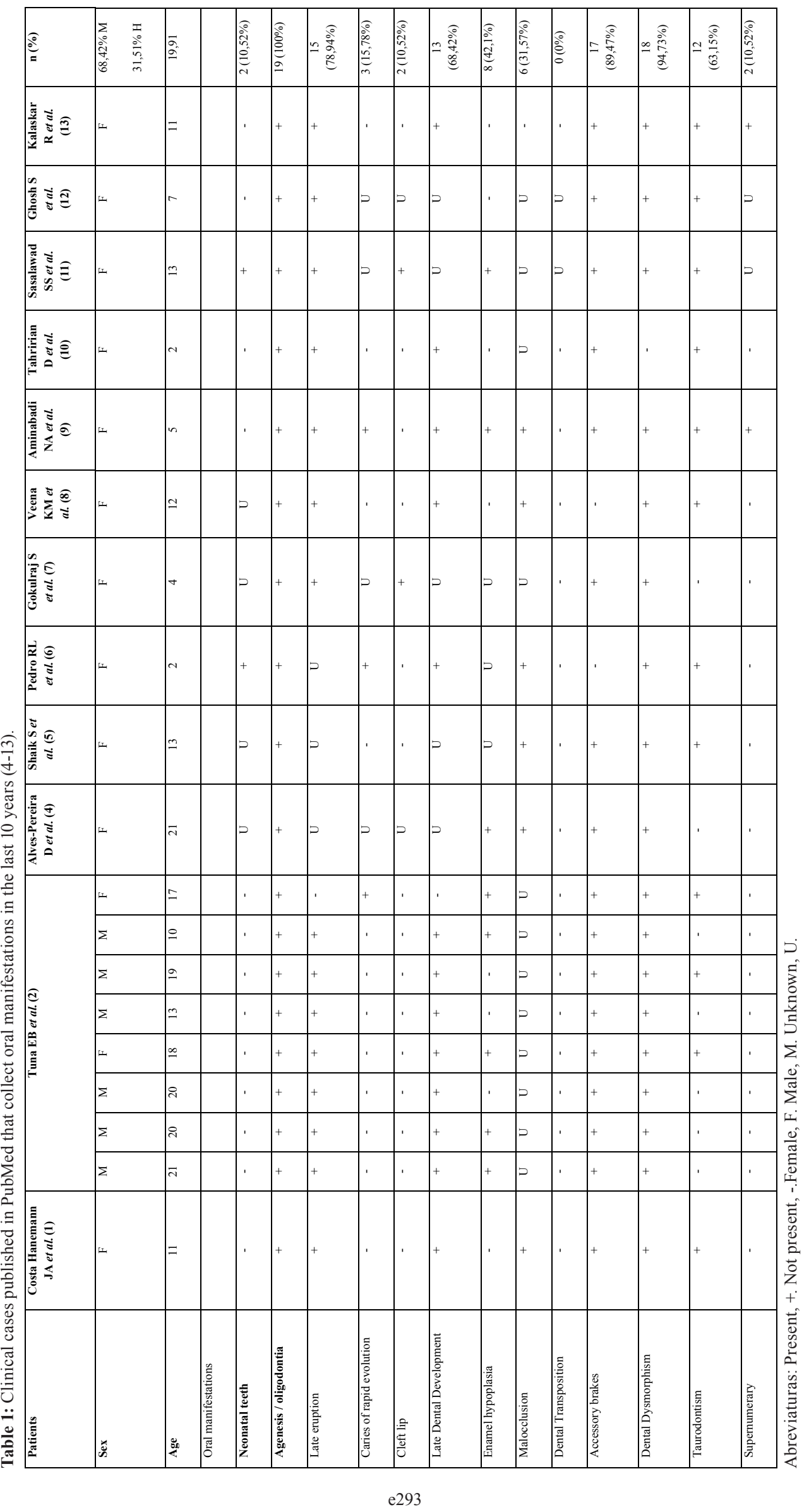


Table 2: Tetrad characteristic in the case report.

\begin{tabular}{|c|c|}
\hline Tetrada feature & Case report \\
\hline Disproporcionate dwarfism & $\begin{array}{ll} & \text { - Disarmonic low size } \\
\text { - } & \text { Rhizomelic short upper and lower extremities } \\
\text { - } & \text { - Small hands and feet } \\
\text { - } & \text { Bilateral transverse palmar fold } \\
\text { - } & \text { - Marked interphalangeal grooves }\end{array}$ \\
\hline Bilateral postaxial polydactyly in hands & $\begin{array}{l}\text { - } \quad \text { Bilateral complete axial polydactyly (hands and feet) } \\
\text { - }\end{array}$ \\
\hline Ectodermal dysplasia & $\begin{array}{ll} & \text { - Severe nail dysplasia } \\
\text { - } & \text { - Agenesies of } 1.2,2.2,3.5,3.2 \text { and } 4.2 \\
\text { - } & \text { - Conoid teeth (Incisors and canines) } \\
\text { - } & \text { - Taurodontism in first permanent molars } \\
\text { - } & \text { - Mesiodens }\end{array}$ \\
\hline Congenital heart malformations & $\begin{array}{ll} & \text { - Affection of the } \mathrm{A}-\mathrm{V} \text { channel with presence of single } \\
& \text { auricle } \\
\text { - } & \text { - Interventricular communication } \\
\text { - } & \text { - Primal ostrium defect } \\
\text { - } & \text { - Systolic murmur of regurgitation } \\
\text { - } & \text { - Tricuspid insufficiency } \\
\text { - } & \text { - Mitral insufficiency }\end{array}$ \\
\hline
\end{tabular}

Table 3: Oral manifestations of EVC syndrome in literature vs case report $(1,5-8,12)$.

\begin{tabular}{|l|c|}
\hline Oral Manifestations according to literature & Oral manifestations in the patient \\
\hline Neonatal teeth & Unknown \\
\hline Partial anodontia & Present \\
\hline Agenesis of upper lateral incisors & Present \\
\hline Agenesis of lower lateral incisors & Present \\
\hline Late eruption & Present \\
\hline Caries of rapid evolution & Present \\
\hline Cleft lip & Not present \\
\hline Late dental development & Present \\
\hline Enamel hypoplasia & Present \\
\hline Malocclusion & Present \\
\hline Dental transposition & Present present \\
\hline Accessory brakes & Not present \\
\hline Dental dysmorphism & Present \\
\hline Taurodontism & Prest \\
\hline
\end{tabular}

Another remarkable finding is the presence of maloclussion, specifically prognatism of the mandible 1 ; our patient presented a tendency to a maloclussion class III and anterior crossbite, due to maxillary compression and partial retention of permanent central incisors (Figs. 2,3).

In reference to the alterations of the dental eruption, an interesting fact present in this case is the poor root deve- 
lopment in permanent first molars and in inferior canines, despite the patient's age.

In general, the statistics shown in Table 1, have coincided with literature, we also have another data reflecting results that help us to understand better the EVC. Case reports articles published in the last ten years describes oral manifestations evidence that dental agenesis has been seen in all cases $(100 \%)$, the dental dimorphism in a total of 18 cases $(94,73 \%)$, accessory frenums in 17 cases $(89,47 \%)$ and late eruption in the $78,94 \%$ of cases, all of them present in the studied case. However, presence of supernumerary teeth is a characteristic which is in the present case but only in 2 of the 19 published cases $(10,52 \%)$.

\section{Conclusions}

EVC syndrome is an infrequent entity and requires a multidisciplinary approach of specialists such as Dentist and Oral and Maxillofacial surgeon. It is important the maintenance of the dental health and to perform a correct dental diagnosis in order to establish an optimal treatment sequence.

\section{References}

1. Costa Hanemann JA, De Carvalho F, Carvalho E, Carnevalli B, Oral Manifestations in Ellis-van Creveld Syndrome: Report of a Case and Review of the Literature. J Oral Maxillofac Surg. 2010;68:456-460.

2. Tuna EB, Koruyucu M, Kürklü E, Çifter M, Gençay K, Seymen F, Tüysüz B. Oral and craniofacial manifestations of Ellis-van Creveld syndrome: Case series. J Craniomaxillofac Surg. 2016;44:919-924.

3. Baujat G, Le Merrer M. Ellis-Van Creveld syndrome. Orphanet J Rare Dis. 2007;2:27.

4. Alves-Pereira D, Berini-Aytés L, Gay-Escoda C. Ellis-van Creveld syndrome. Case report and literature review. Med Oral Patol Oral Cir Bucal. 2009;14:E340-343.

5. Shaik S, Raviraj J, Dirasantchu S, Venkata SS. Ellis-van Creveld syndrome with unusual oral and dental findings: A rare clinical entity. Dent Res J. 2016;13:193-197.

6. Pedro RL, Andrade LH, Maia LC. The importance of oral-clinical findings for the correct diagnosis of Ellis-van Creveld syndrome. Gen Dent. 2011;59:e206-209.

7. Gokulraj S, Mohan N, Raj B, S. Ahamed Y, Arokiaraj S, Subbulakshmi C. Ellis-Van Creveld syndrome in siblings: A rare case report. J Pharm Bioallied Sci. 2016;8:S179-S181.

8. Veena KM, Jagadishchandra H, Rao PK, Chatra L. Ellis-van Creveld syndrome in an Indian child: a case report. Imaging Sci Dent. 2011;41:167-170.

9. Aminabadi NA, Ebrahimi A, Oskouei SG. Chondroectodermal dysplasia (Ellis-van Creveld syndrome): a case report. J Oral Sci. 2010;52:333-336.

10. Tahririan D, Eshghi A, Givehchian P, Tahririan MA. Chondroectodermal Dysplasia: A Rare Syndrome. J Dent. 2014;11:361-364.

11. Sasalawad SS, Hugar SM, Poonacha KS, Mallikarjuna R. Ellis van Creveld syndrome. BMJ Case Rep. 2013;2013. pii: bcr2013009463.

12. Ghosh S, Setty S, Sivakumar A, Pai KM. Report of a new syndrome: focus on differential diagnosis and review of Ellis-van Creveld, Curry-Hall, acrofacial dysostosis, and orofacial digital syndromes. Oral Surg Oral Med Oral Pathol Oral Radiol Endod. 2007;103:670676.

13. Kalaskar R, Kalaskar AR. Oral manifestations of Ellisvan Creveld syndrome. Contemp Clin Dent. 2012;3:S55-S59.

Conflict of Interest

The authors have declared that no conflict of interest exist. 